\title{
The exercise class experience: an opportunity to promote student wellbeing during the HSC
}

\author{
Danielle Hagarty \\ Researcher \\ Faculty of Arts and Social Sciences \\ University of Technology, Sydney \\ Australia \\ Janet Currie \\ Senior Lecturer \\ Faculty of Arts and Social Sciences \\ University of Technology, Sydney \\ Australia
}

\begin{abstract}
Research has revealed that approximately 40 per cent of Year 12 HSC students and 25 per cent of Year 11 HSC students experience symptoms of depression, anxiety and/or stress, which exceeds the normal or expected values. Numerous studies show that female students report higher levels of psychological distress than their male counterparts. Female secondary school students also report poor lifestyle behaviours such as low levels of participation in physical activity. This is despite research demonstrating that physical activity interventions are an effective means of promoting wellbeing. However, it has not been well documented whether HSC students consider physical activity interventions to be beneficial at this stressful time of their lives. Therefore, the current study explores the experiences of a group of female HSC students ( $\mathrm{n}=6$, mean age $=17$ years) who participated in a once-per-week, 8-week exercise class program. Each participant reported at least one perceived benefit relating to their involvement in the program. The participants identified a perceived increased level of access to physical activity. After taking part in the program, participants also identified reductions in individual subjective stress, increased social interaction,
\end{abstract}


improved self-esteem and improved mood states as perceived benefits of exercise class participation. We recommend that secondary schools in Australia focus on providing supportive environments for health by offering HSC students the chance to take part in conveniently located, free-of-charge exercise classes.

\section{Introduction}

Research suggests that completion of final secondary school examinations is a demanding process that has the capacity to impact negatively on the health and wellbeing of students (Einstein, Lovibond and Gaston 2000; Hodge, McCormick and Elliott 1997; McGraw et al. 2008; Robinson, Alexander and Gradisar 2009; Smith 2004; Smith and Sinclair 2000). This trend is evident in health data indicating that students completing their final years of secondary schooling experience levels of depression, anxiety and/or stress exceeding the 'normal' or expected values (Einstein, Lovibond and Gaston 2000; Hodge, McCormick and Elliott 1997; McGraw et al. 2008; Robinson et al. 2009; Smith 2004; Smith and Sinclair 2000, 2002). For example, a recent major study conducted in South Australia revealed that levels of depression, stress and anxiety detected among final year secondary students also surpassed normal or expected values. Greater than 10 per cent of male students and 20 per cent of female students reported severe or extremely severe levels of depression, anxiety and/or stress symptoms (Robinson et al. 2009).

\section{Perceived sources and effects of HSC-related stress}

Elevated stress levels during the Higher School Certificate (HSC) may be attributed to a variety of sources (Smith and Sinclair 2000). The use of HSC marks to determine who gains entry into competitive tertiary courses produces an atmosphere of pressure for some students. It can influence students to perceive the HSC as having 'lifelong' significance or an influence on one's ultimate career (Smith and Sinclair 2000). Additionally, the increased study workload experienced during this stage, perceived external pressure from parents and teachers, and low self-efficacy have been identified as contributing factors to heightened stress levels during this final phase of schooling (Smith 2004).

Elevated stress associated with the HSC has been linked with poor academic performance, decreased self-efficacy and decreased self-esteem (Smith 2004). However, some students experience levels of stress evoking more serious concern. McGraw et al. (2008) revealed that approximately 20 per cent of HSC students in a relatively large sample reported having thoughts of self-harm. In addition, a report by the NSW Commission for Children and Young People revealed that 10 suicides between 1996 and 2000 were linked with HSC stress (Robinson et al. 2009).

As well as experiencing the direct health impacts of 'HSC-related stress', this stage of schooling can have a negative impact on a student's overall quality of life (McGraw et al. 2008). Robinson et al. (2009) revealed that a number of students experience sleep disturbances including a lack of sleep, which interacts with study demands in multiple ways. That is, the increased workload and stress during this phase of schooling impacts on time available to sleep and the quality of sleep 
experienced. On the other hand, a lack of sleep impacts on a student's ability to study effectively and to cope with the demands and stress of student life during the final school year (Robinson et al. 2009).

A lack of family, peer and school connectedness during the final years of secondary schooling is also linked with elevated levels of depression, anxiety and/or stress (McGraw et al. 2008). The reduction in a student's level of connectedness with their family and peers is due to the demands that Year 12 places on a student's time availability and stress levels, causing a significant strain on relationships. McGraw et al. (2008) also stated that a lack of connectedness can heighten the stress a student experiences during this phase of schooling. However, maintaining healthy relationships with family and peers can act as a protective factor for psychological health and wellbeing (McGraw et al. 2008).

\section{Reducing the burden of HSC stress}

Easing the competitive nature of the HSC and eliminating the idea of "winners and losers' has been one strategy proposed by policy makers to help reduce stress caused by the HSC (Smith and Sinclair 2000). Smith and Sinclair (2000) also argue, however, for more consideration to be given to the motivational styles of students, methods of dealing with stress and with negating poor mood associated with completing the HSC.

A number of programs have since been designed to address the psychological wellbeing of HSC students; however only one known health promotion intervention has previously been published in this field (Currie 2010). Robinson et al. (2009) cited the lack of research conducted as being due to the concerns of teachers and parents about the potential stress and disruption to students as a result of them participating in research projects on top of existing workloads.

Generally, psychological intervention and counselling is the method most often recommended for students experiencing stress associated with the HSC (Gaston 2008). A number of programs have also evolved that attempt to educate students about coping and stress management strategies for use during the HSC. The 'Taking Charge - Management of Stress, Anxiety and Depression' program run by the Health Psychology Unit at University of Technology, Sydney (UTS) is designed to equip students with personal skills to help enable them to 'take control' of upsetting emotions (UTS 2009a). The 'Taking Charge' program is run in groups for students in Years 10, 11 and 12 who are experiencing high levels of stress, or symptoms of anxiety or depression. The program runs for eight weekly sessions of $1 \frac{1}{2}$ hours each, and aims to teach participants a range of coping strategies to help them manage some of the challenges that they are dealing with.

The program targets students who may be experiencing worry; anxiety; depression; low self-confidence; problems with peers, family or school; withdrawal from friends or family; physical symptoms such as headaches, sleep problems and exhaustion; and concerns about the future. The program aims to equip participants with various practical strategies to help them manage their mood, solve problems and overcome obstacles to making progress. Topics covered in the program include identifying the 
triggers to stress, reactions, problem solving, challenging self-defeating thoughts and 'self-talk', setting goals, effective communication, mood enhancing techniques, improving self-esteem and managing anxiety.

The Health Psychology Unit's 'Managing HSC Stress' program is also run free of charge in small groups for students in Years 11 and 12 who are undertaking the HSC, or HSC subjects. The program runs for four weekly sessions of $1 \frac{1}{2}$ hours per session, and aims to provide participants with a range of coping strategies to help them manage some of the challenges associated with Year 12. The program targets students who may be experiencing high levels of stress, anxiety or frustration, depressed mood, difficulties with time management, procrastination, poor concentration, withdrawal from friends or family, or physical symptoms such as headaches, sleep problems and exhaustion. The program is also run in small groups. Within a friendly and supportive environment participants learn coping strategies and talk to other students who are experiencing similar situations. Topics covered in the program include understanding the stress reaction, identifying personal stressors, identifying and challenging self-defeating thoughts, or 'self-talk', problem solving, positive actions to reduce stress, relaxation techniques and goal setting.

'The program teaches skills that can be helpful in any stressful situation', said UTS health psychologist Megan Varlow:

\footnotetext{
It can also be useful for students who are struggling with anxiety, low self-esteem or low mood. It's about understanding what triggers stress and how some simple planning and organisational tools can head it off long before it gets to the panic stage. The beginning of the year is the time to get those skills in place. By the time exams are looming there's much less chance of being able to take a step back and change how you're thinking. (UTS 2009b)
}

The Health Psychology Unit is part of the UTS Faculty of Science and offers the free programs at its premises adjacent to the Royal North Shore Hospital at St Leonards, Sydney, or on-site at individual schools, as requested.

Macquarie University offers a similar program, called the 'Study without Stress Program' (Macquarie University 2011). 'Study without Stress' is a new program being offered at the Macquarie University's Emotional Health Clinic. It has been specifically designed to target the difficulties many students express they have in coping with the building stress during Years 10, 11 and 12. The program teaches students cognitive and behavioural skills to manage the stress of the increased workload and pressure for performance associated with the HSC, including understanding stress, stress management, challenging unhelpful thinking styles, managing high workloads, dealing with exam anxiety, tips for managing procrastination, tips for keeping perfectionism under control, problem solving and creating a study-life balance.

The clinic describes the program as ideal for students already experiencing high stress levels. However, it is also very beneficial for students who are in the early stages of the HSC, to learn skills to deal with the increased stress that they will face as the HSC period continues. The Macquarie University program is individually tailored to each adolescent client, in a one-to-one format. However, the program 
involves fees similar to private clinician or psychologist rates (Macquarie University 2011).

These particular programs play a significant role in managing and supporting students experiencing depression, anxiety and/or stress during the HSC. However, there is a clear need for further research into self-help and preventive lifestyle approaches that may empower students to adopt ongoing forms of self-administered stress management or enhanced wellbeing.

\section{Physical activity strategies addressing HSC stress}

The poor lifestyle behaviour patterns currently prevalent among female HSC students indicate a great deal of room for improvement. Rates of physical activity are alarmingly low among Australian students, particularly girls. Results of the NSW Schools Physical Activity and Nutrition Survey (Booth et al. 2006) showed that 31.7 per cent of adolescent girls do not engage in sufficient physical activity. Another study revealed that only 10.8 per cent of female final year students are sufficiently active (Scully et al. 2007). An important point to consider is the consistent decline in physical activity participation with age (Booth et al. 2006). These patterns emerging from the wider literature indicate that the period of adolescence forms a critical window of opportunity to promote and increase physical activity participation for females and to prevent longer-term drop-out.

These trends of poor participation peaking at Year 11 and 12 occur when the 'compulsory' sport that was part of the regular Years 7-10 physical education curriculum ceases to be part of the senior student's regular school routine. Opportunities to access free, conveniently scheduled and enjoyable, safe programs of choice available through school sport therefore dramatically decreases at a time when students may ironically be most inactive because of high study loads.

Currie (2010) investigated the experiences of female HSC students participating in an exercise class program. Similar to the aims of this study, Currie explored the experiences of a group of eight HSC students in Sydney, Australia (mean age $=18$ years) participating in a pilot program of weekly exercise classes for 10 weeks. The exercise classes were comparable to this study's, involving a warm-up, low-impact aerobic exercises, muscle conditioning, cool down and relaxation components, all with a music background. However the classes were made available at an offcampus, community-based location. The focus group data revealed that for the students the main reasons for attending included to gain mental and physical fitness benefits. Students mentioned feeling more focused and able to study following the class. The findings suggested that taking part in exercise classes offered a simple and effective strategy to assist HSC students to cope more effectively with exam stress.

While Currie's (2010) study showed that the program seemed initially acceptable to the target group, transport was considered a barrier. Also, the researchers concluded that further research in additional settings using data triangulation was warranted to assess the feasibility of the program. As a result of the first concern, our study 
offered classes at an 'on-site' school setting, with the hope of increasing convenience and accessibility for students.

A study conducted in India found that physical activity participation in the form of yoga had significant benefits in reducing academic stress and enhancing wellbeing among secondary students (Venkataramana, Poomalil and Shobhasree 2008). Although research on this topic is fairly limited, it does suggest the possible success of an intervention designed to increase physical activity participation as a means of targeting the issue of student mental health and wellbeing during the HSC (Hagarty and Currie 2010). Furthermore, students could possibly gain the wider lifelong benefits and lifestyle skills that participation in physical activity may offer. While one-on-one counselling may be beneficial for the extremely stressed student, participation in physical activity may be a more preventive and sustainable health promotion strategy.

It is important that students in the final years of secondary schooling maintain healthy lifestyle behaviours to help optimise academic performance and maintain a sense of wellbeing. The wider exercise science research demonstrates the mental health benefits of engaging in physical activity (Craft et al. 2007; Ströhle 2009; Greenwood and Fleshner 2008; Knapen et al. 2009). However, with the paucity of research to date evaluating the mental health and wellbeing benefits of a physical activity intervention designed for HSC students, this study aimed to further investigate the experiences of a group of female HSC students who participated in an 8-week exercise class program.

\section{Method}

A sample of convenience including six female HSC students (mean age $=17$ years) took part in a group exercise class conducted within two schools, once per week for 8 weeks during the second school term of the year in Sydney, Australia ( $n=4$ at High Hills Secondary School, $n=2$ at Ocean View High). We used a purposeful sampling technique as outlined by Patton (1990) to access information of central importance to the study, that is, the experiences of female HSC students taking part in the program. The exercise class program consisted of one-hour 'aerobics' classes with warm-up, aerobic conditioning, muscle conditioning, stretching and relaxation components held during a free period at the students' own school setting and led by one of the researchers. The participants were those students who responded to flyers placed around the school advertising the free classes and voluntarily turned up at the classes. Prior to the commencement of the study, ethical approval was obtained from the Human Research Ethics Committee at the University of Technology, Sydney. All participants were categorised as 'apparently healthy' according to the Sports Medicine Australia (2005) Pre-activity Screening Questionnaire. Table 1 below outlines a brief description of each participant. 
Table 1: Participant personality types

\begin{tabular}{ll}
\hline Name & Personality description \\
\hline Esther & $\begin{array}{l}\text { Esther is a very quiet and reserved student. She is } \\
\text { very studious and ambitious with clear, } \\
\text { significant goals for the HSC. Esther is generally } \\
\text { not very outgoing or overly confident with regard } \\
\text { to participating in physical activity. }\end{array}$ \\
Chardonnay & $\begin{array}{l}\text { Chardonnay is a dedicated and diligent student. } \\
\text { She places a great deal of importance on the HSC } \\
\text { yet also displays a sense of priority in terms of } \\
\text { maintaining a healthy lifestyle. }\end{array}$ \\
Katie is a very outgoing, social and lively student. \\
She is quite comfortable with taking part in all \\
forms of physical activity and has a clear passion \\
for health and fitness. \\
Jasmine is a sociable, enthusiastic and confident \\
student. She lacks confidence with some forms of \\
physical activity but is very willing to participate \\
regardless.
\end{tabular}

We adopted an exploratory technique using a grounded theory approach to evaluate the participants' experiences. Qualitative data collection methods help provide depth, detail and access to the individual perspectives of the participants (Patton 1990). Therefore we used techniques including questionnaires, focus group interviews and participant observation to help gain a clearer understanding of participants' thoughts, feelings and lived experiences regarding the exercise program within the context of their daily lifestyles. 
The instruments included an initial written questionnaire investigating perceptions of physical activity. This was completed prior to the commencement of the 8-week exercise class program. The researcher/class leader maintained a participant observation diary, consisting of notes taken by her regarding the participants' behaviour at every weekly class. An interview schedule consisting of broad, openended questions regarding the participants' general experiences of completing the HSC and their experiences within the program were used to guide the focus group conversations. A final written questionnaire was completed at the conclusion of the 8 weeks to access overall feedback on the exercise program and participant experiences as a whole.

The data were transcribed verbatim onto a word processing package and analysed using the grounded theory techniques outlined by Strauss and Corbin (1998). We conducted a microanalysis whereby the data was read carefully and coded systematically. We adopted an open-coding process in which we examined each sentence closely and designated a relevant concept label (Strauss and Corbin 1998). Following the open-coding process, we applied an axial-coding technique. We fractured and reorganised the data by relating similar concepts in order to identify the major themes and categories present within the data (Strauss and Corbin 1998). The next section reports the main findings of the study.

\section{Findings}

When we asked the participants to describe the overall experience of participating in the 8-week exercise class program, a number of themes and concepts arose. Throughout the data collection process, it was often evident that the participants felt that as a result of taking part in the program they had immediately improved their access to physical activity. The program was typically described as an 'opportunity to stay active during the HSC' (Jasmine). Participants described the program as having the capacity to increase their level of motivation to take part in physical activity within the program and also in addition to the program. It was described as a 'dose-response' relationship, that is, the more classes they attended, the more they were motivated to attend and even to feel like participating in other forms of physical activity.

All participants believed that the program provided benefits including reduction in stress levels and an overall improvement in general health and wellbeing. Two comments illustrating this concept included one from Katie, who said, 'I found the program overall really helpful in terms of relieving stress', and Jasmine, stating 'My overall wellbeing has improved immensely through my participation in this program'. Chardonnay stated that 'It has been very helpful in minimising my stress levels especially concerning school', while Jasmine revealed that her involvement within the exercise class program helped her to feel empowered in terms of dealing with stress. At the conclusion of the 8-week program, Jasmine said, 'I feel like I am more capable of dealing with stress and I find it surprising that I don't experience great stress at exam times, for now anyway'. These findings exemplify those of Greenwood and Fleshner's (2008) study, showing that 'longer-term' stress relief resulting from participation in physical activity may be associated with neural adaptations that improve the brain's susceptibility to stress. 
Improvements in self-esteem were another common benefit identified by all students, with Katie explaining, 'It's given me more confidence to do things and makes me feel better about myself'. Improving self-esteem was defined as 'mak[ing] the girls feel better about themselves'. Katie described this phenomenon: when 'I've just done some exercise and it makes me feel good'. Similarly, Chardonnay said, 'When I do the exercise I feel better about myself'. It might be possible that these improvements were linked to the esteem support or bolstering of the girl's sense of competence provided by the instructor's positive feedback or from 'mastering' the exercises in the class itself (Carless and Douglas 2010).

Social interaction was also seen as a benefit of taking part in the program. Chardonnay stated, 'Exercising while hanging out with friends keeps me motivated'. Jasmine linked the social aspects of the program with helping her to become more active, as 'Being with other people has given me the opportunity to break down the barriers'. The researcher observed that the program provided an opportunity for students to socialise while taking part in the classes. The girls would laugh and talk to each other throughout the program and appeared as though they were enjoying the social aspect of the program. During the weekly classes the researcher also observed that students would often walk past the exercise class, observe their peers and ask if they could join in. Each week participants would often arrive at the class with a friend and patterns began to emerge whereby if one person was absent their friend(s) were likely to be also.

Finally, four out of the six participants reported perceiving improvements in their subjective wellbeing immediately following the exercise classes. They described this as an enhancement of mood or feeling happier and more energised. Jasmine described her experience as 'feeling more rejuvenated and energised'. They described the program as a fun and enjoyable experience with the capacity to boost their energy levels, increase their happiness and provide something to look forward to: 'I always looked forward to participating' (Chardonnay). This finding is consistent with the wider literature which shows a positive correlation between physical activity and improvements in mood state, even following a single session (Hoffman and Hoffman 2007).

The findings suggest that exercise class participation may provide opportunities for improved social and emotional wellbeing among female HSC students. Figure 1 encapsulates the main themes to emerge from the qualitative data, from the students' point of view. Increases in subjective social and emotional wellbeing included perceived reductions in stress, increased social interaction, and improved mood, self-esteem and self-efficacy. These findings are consistent with the wider literature regarding physical activity and its capacity to confer improvements in social and emotional wellbeing (Church and Blair 2009; Jiménez et al. 2008; Rennemark et al. 2009; Ströhle 2009). It is widely reported in the exercise science and sports psychology research that physical activity has a small-to-moderate beneficial effect on anxiety reduction and stress reactivity (Biddle and Mutrie 2001). It is also believed that physical activity can act as a 'distraction' from unpleasant events or negative stimuli. This subsequently plays a key role in reducing stress levels $(\mathrm{Ng}$, Dodd and Berk 2007). 


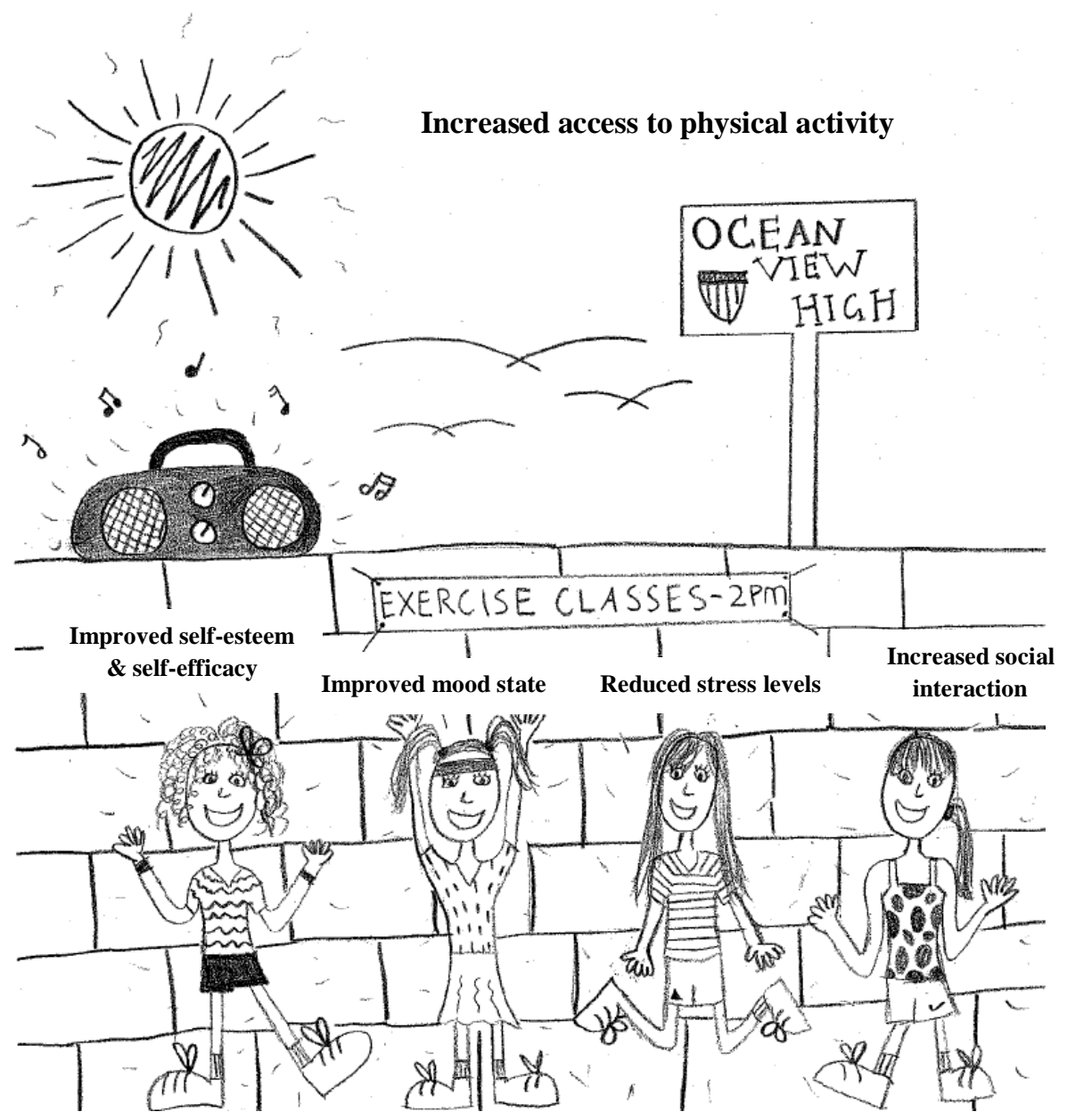

Figure 1: The perceived opportunities for experiencing perceptions of wellbeing associated with exercise class participation among female HSC students (Illustration: Hagarty, 2011)

According to the students, participation was characterised by perceived increased access to physical activity and social interaction benefits. Social support and interaction is a key factor likely to motivate participation in physical activity (Neumark-Sztainer et al. 2003). Physical activity research points to the increased social connectedness made possible from relationship building, social support, shared experiences, activities and interactions with others. Physical activity incorporating moving together as a group or opportunities for social interactions and connection may offer a relational orientation, which may be more appealing to women than a performance-oriented involvement (Carless and Douglas 2010). This holistic social experience inherent in the physical activity might have been the primary factor promoting relief from the day-to-day stresses of the HSC experience for this group of students. The next section discusses the findings. 


\section{Discussion}

Each student linked participation in the classes with at least one perceived benefit. Perceived individual improvements in subjective mental health and wellbeing associated with the exercise classes were the most significant changes experienced by all participants. The program offered an opportunity for social interaction and provided a healthy 'distraction' from the worries and stress of HSC life. These findings are consistent with those regarding improvements in acute and overall mood state following exercise (Hoffman and Hoffman 2007; Peluso and Andrade 2005). The findings regarding stress relief and relaxation associated with the program are congruent with the related literature (Greenwood and Fleshner 2008; Knapen et al. 2009; Raglin 1990; Salmon 2001). Increased self-esteem associated with participation in the program is consistent with Spence, McGannon and Poon's (2005) findings, and increased motivation to be physically active through increased self-efficacy regarding physical activity is consistent with Dishman et al.'s (2004) findings.

The findings of the current study have led to the development of the grounded theory that exercise classes might promote social and emotional wellbeing among female HSC students. Participation in the classes had a positive impact on various aspects of the participants' reported health and lifestyle, specifically perceived subjective social and emotional wellbeing. The students also identified that engaging in these activities increased their perceived motivation levels regarding physical activity participation, thus fostering the greater inclusion of health-promoting behaviours as part of their overall lifestyles. Figure 2 provides a diagrammatic representation of the theory for perceived improvements to wellbeing expressed by participants related to taking part in the program. 


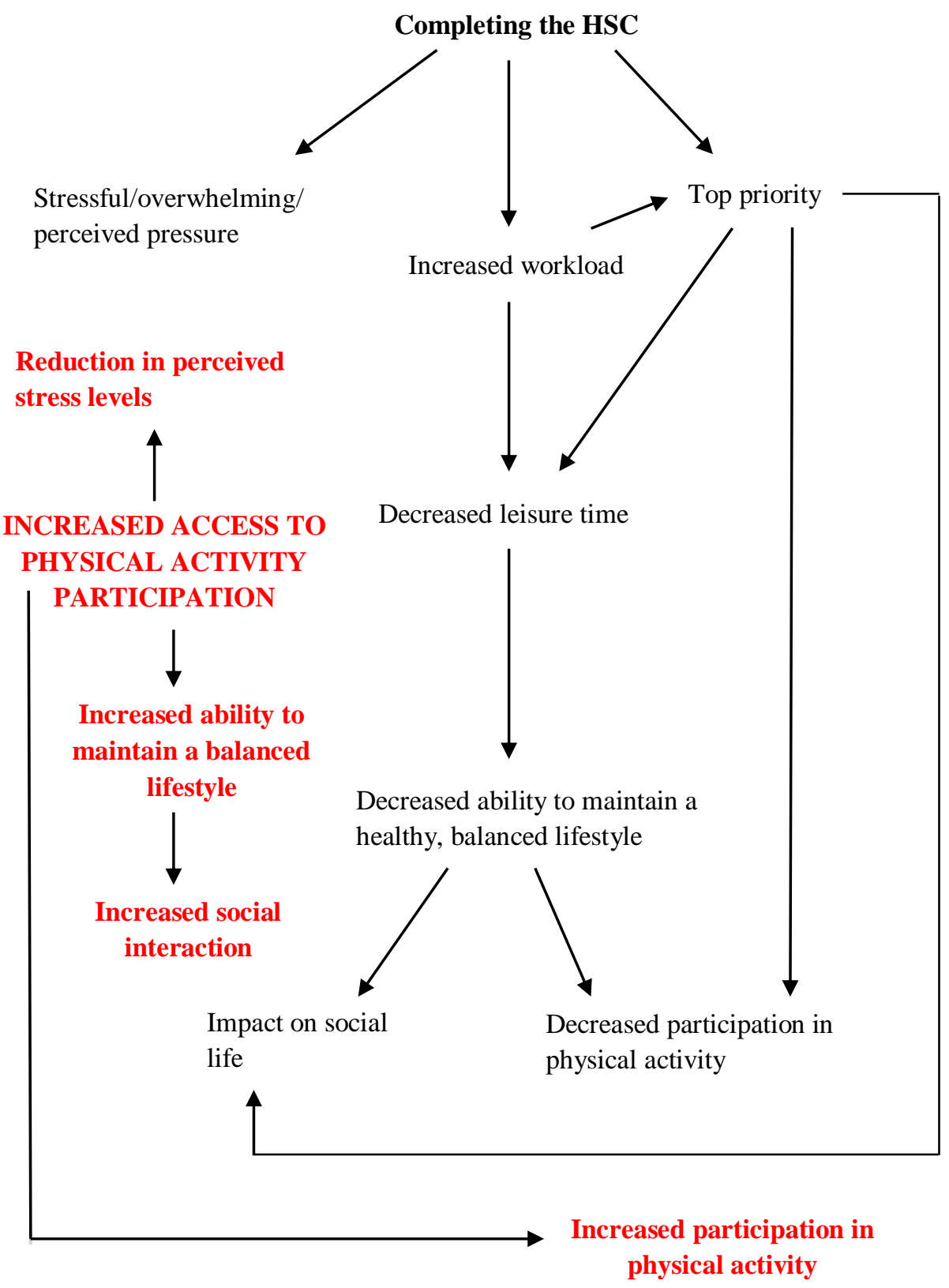

Figure 2: Perceived benefits of exercise class participation among female HSC students

The mechanisms of the relationship reported by the participants between physical activity and increased wellbeing may include increased social interaction through exercise class participation, social support and connectedness, improved mood states, and increased self-efficacy and resilience. These findings are consistent with 
Currie's (2010) study, which concluded that the social aspect of an exercise class program was a key factor in instigating participation. A student's friend(s) also need to attend and find the class 'fun'. The current study's findings emphasise the role of social interaction and networking in designing and implementing physical activity programs for adolescent girls. It also reveals the potential influence of peer factors when encouraging girls to be physically active. Social interaction can be the initial incentive for taking part in physical activity and participation, especially in a group setting; however the activity can also foster opportunities for developing new friendships and connections. Lastly, social interaction can help to sustain participation in physical activity by acting as an additional reason or motive to adhere to a program.

As this study was limited to evaluating the benefits of physical activity participation in the form of exercise classes, further research might investigate a broader range of physical activities, for example, walking groups or social team sports. This would enable future researchers to explore the relationship between activity type and any associated social or emotional wellbeing benefits. Secondly, the current study predominantly used subjective qualitative data collection methods. We recommend that objective measures for evaluating improved social and emotional wellbeing among female HSC students related to their exercise class participation be incorporated within future studies. In order to help validate the outcomes, subsequent studies could incorporate psychological inventories such as the Depression Anxiety Stress Scale (used prior to and at the conclusion of the exercise class program). This may be useful in providing further evaluation of physical activity interventions in terms of their capacity to assist with mental wellbeing during the HSC period. Measures of social connectedness and social interaction such as the Social Connectedness Scale (Lee and Robbins 1995) may also provide an objective evaluation of the program's ability to influence social wellbeing.

Participants were recruited from two private secondary schools within Sydney. These particular schools have been reported on the federal government's MySchool website as having 'Community Socio-Educational Advantage' indexes of 1070 and 1172. These scores are above average and towards the upper limit of community socio-educational advantage. Therefore, participants were most likely to be from higher socioeconomic backgrounds. This could be considered a limitation of the study as the participants might already have been experiencing higher levels of overall health and wellbeing and physical activity participation in contrast with students from lower socioeconomic backgrounds.

Due to study approval conditions, this study was limited to accessing students and conducting the classes during Term 2 of the school year. While the participants' perceived stress levels may be have been higher during Term 2 than Term 1, overall levels of HSC-related stress might be higher during Term 3. This is because Term 3 includes the lead-up to the final examinations. Therefore it is not known if the intervention would still be considered as helpful at a more stressful or intense time of the year. The principal researcher conducting the investigation was also the instructor for the exercise class program. This may be considered a possible limitation within the study as the participants may have withheld negative opinions 
regarding their experiences. Also, the group was aware of the researcher's background in health studies, which may have prompted them to provide favourable responses as a means of pleasing or impressing the researcher.

Finally, we found the process of gaining approval for research involving HSC students and then gaining access to the students to be a difficult one. As a result, participant numbers and the types of schools involved in the study were limited. This is a major practical reason for the paucity of research conducted on the area. It was our experience, however, that some teachers appeared too stressed and overburdened by the 'whole HSC experience' to wish to become involved and offer the program for the students. Some teachers within High Hills Secondary School expressed concern about student involvement in a research project. They indicated that they felt participation in the study would be likely to place an extra burden on the students and possibly increase stress levels. Statements such as, 'The girls are quite stressed, you know?' and 'It's a really busy time for the students; they really don't have much spare time' represented the general outlook regarding involvement in the study. This is consistent with Robinson et al.'s (2009) explanation for the lack of research that has been conducted to date among this subgroup. Further research should be carried out to investigate stress levels and the impact of the 'HSC year' for teachers, parents and families, as well as students. We believe that wider support for the program is required in future from school leadership and government authorities for it to be a wider success. We also recommend that future studies incorporate a wider demographic to assess the feasibility of exercise class programs for students from a diverse range of socioeconomic and cultural backgrounds.

In conclusion, the findings of the current study suggest that exercise class participation may offer students the chance to improve their social and emotional wellbeing during the HSC period. Providing opportunities for participation in physical activity programs may be a convenient and cost-effective strategy to promote mental health among the wider student community and target the issue of HSC-related stress. It is also important that interventions designed for HSC students provide opportunities for social interaction. We recommend that classes be conducted within supportive and convenient environments offering students the chance to take a healthy break from their demanding study schedules.

\section{References}

Biddle, SJH and Mutrie, N 2001, Psychology of physical activity, Routledge, London.

Booth, M, Okely, AD, Denney-Wilson, E, Hardy, L, Yang, B and Dobbins, T 2006, NSW Schools Physical Activity and Nutrition Survey (SPANS) 2004, NSW Department of Health, Sydney.

Carless, D and Douglas, K 2010, Sport and physical activity for mental health, Blackwell Publishing, Oxford. 
Church, TS and Blair, SN 2009, 'When will we treat physical activity as a legitimate medical therapy ... even though it does not come in a pill?' British Journal of Sports Medicine, vol. 43, pp. 80-81.

Craft, LL, Freund, KM, Culpepper, L and Perna, FM 2007, 'Intervention study of exercise for depressive symptoms in women', Journal of Women's Health, vol. 16, pp. 1499-1509.

Currie, J 2010, 'Perceived benefits of exercise class participation for female HSC students', International Journal of Sport and Society, vol. 1, pp. 203-210.

Dishman, RK, Motl, RW and Saunders, R et al. 2004, 'Self-efficacy partially mediates the effect of a school-based physical-activity intervention among adolescent girls', Preventive Medicine, vol. 38, pp. 628-636.

Einstein, DA, Lovibond, PF and Gaston, JE 2000, 'Relationship between perfectionism and emotional symptoms in an adolescent sample', Australian Journal of Psychology, vol. 52, pp. 89-93.

Gaston, J 2008. Stress, anxiety and the HSC, Anxiety Research Centre for Emotional Health, Macquarie University, Sydney.

Greenwood, BN and Fleshner, M 2008, 'Exercise, learned helplessness, and the stress-resistant brain', Neuromolecular Medicine, vol. 10, pp. 81-98.

Hagarty, D and Currie, J 2010, 'Exercise as therapy for HSC stress: who, what, when, where and how?', paper presented at the 11th International Mental Health Conference, Gold Coast, 18-20 August.

Hodge, GM, McCormick, J and Elliott, R 1997, 'Examination-induced distress in a public examination at the completion of secondary schooling', British Journal of Educational Psychology, vol. 67, no. 2, pp. 185-197.

Hoffman, MD and Hoffman, DR 2007, 'Does aerobic exercise improve pain perception and mood? A review of the evidence related to healthy and chronic pain subjects', Current Pain and Headache Reports, vol. 11, pp. 9397.

Jiménez, MG, Martínez, P, Miró, E and Sánchez, AI 2008, 'Bienestar psicológico y hábitos saludables: ¿ están asociados a la práctica de ejercicio físico', International Journal of Clinical and Health Psychology, vol. 8, pp. 185202.

Knapen, J, Sommerijns, E and Vancampfort, D et al. 2009, 'State anxiety and subjective well-being responses to acute bouts of aerobic exercise in patients with depressive and anxiety disorders', British Medical Journal, vol. 43, pp. 756-759. 
Lee, RM and Robbins, SB 1995, 'Measuring belongingness: the social connectedness and the social assurance scales', Journal of Counseling Psychology, vol. 42, pp. 232-241.

Macquarie University 2011, Study without Stress Program, http://www.emotionalhealthclinic.com.au/index.cfm?page_id=1356 (accessed 15 June 2011).

McGraw, K, Moore, S, Fuller, A and Bates, G 2008, 'Family, peer and school connectedness in final year secondary school students', Australian Psychologist, vol. 43, pp. 27-37.

Neumark-Sztainer, D, Story, M, Hannan, PJ, Tharp, T and Rex, J 2003, 'Factors associated with changes in physical activity: a cohort study of inactive adolescent girls', Archives of Pediatrics and Adolescent Medicine, vol. 157, pp. 803-810.

$\mathrm{Ng}, \mathrm{F}$, Dodd, S and Berk, M 2007, 'The effects of physical activity in the acute treatment of bipolar disorder: a pilot study', Journal of Affective Disorders, vol. 101, pp. 259-262.

Patton, MQ 1990, Qualitative evaluation and research methods, Sage, Newbury Park, CA.

Peluso, MA and Andrade, LH 2005, 'Physical activity and mental health: the association between exercise and mood', Clinics, vol. 60, pp. 61-70.

Raglin, JS 1990, 'Exercise and mental health: beneficial and detrimental effects', Sports Medicine, vol. 9, pp. 323-329.

Rennemark, M, Lindwall, M, Halling, A and Berglund, J 2009, 'Relationships between physical activity and perceived qualities of life in old age: results of the SNAC study', Aging and Mental Health, vol. 13, pp. 1-8.

Robinson, JA, Alexander, DJ and Gradisar, MS 2009, 'Preparing for Year 12 examinations: predictors of psychological distress and sleep', Australian Journal of Psychology, vol. 61, pp. 59-68.

Salmon, P 2001, 'Effects of physical exercise on anxiety, depression, and sensitivity to stress: a unifying theory', Clinical Psychology Review, vol. 21, pp. 33-61.

Scully, M, Dixon, H, White, V and Beckmann, K 2007, 'Dietary, physical activity and sedentary behaviour among Australian secondary students in 2005', Health Promotion International, vol. 22, p. 236.

Smith, L 2004, 'Changes in student motivation over the final year of high school', Journal of Educational Enquiry, vol. 5, pp. 64-85. 
Smith, L and Sinclair, KE 2000, 'Stress and learning in the Higher School Certificate', Change: Transformations in Education, vol. 3, pp. 67-79.

Spence, JC, McGannon, KR and Poon, P 2005, 'The effect of exercise on global self-esteem: a quantitative review', Journal of Sport and Exercise Psychology, vol. 27, p. 311.

Strauss, A and Corbin, J 1998, Basics of qualitative research: techniques and procedures for developing grounded theory, Sage, Thousand Oaks, CA.

Ströhle, A 2009, 'Physical activity, exercise, depression and anxiety disorders', Journal of Neural Transmission, vol. 116, pp. 777-784.

University of Technology, Sydney (UTS) 2009a, Taking Charge - Management of Stress, Anxiety and Depression, http://www.science.uts.edu.au/centres/psych/services.html\#taking (accessed 12 March 2010).

University of Technology, Sydney (UTS) 2009b, Free program offers early start on beating HSC stress, http://newsroom.uts.edu.au/news/2009/01/free-programoffers-early-start-on-beating-hsc-stress (accessed 15 June 2011).

Venkataramana, HL, Poomalil, SN and Shobhasree, T 2008, 'Effect of yoga on academic stress of high school students', Social Science International, vol. 24, pp. 89-97. 